Bol. Acad. peru. leng. 50. 2010 (167-180)

\title{
CARLOS ROBLES RÁZURL UNA VIDA DEDICADA A FORJAR LA CULTURA LETRADA DE PIURA
}

\author{
CARLOS ROBLES RÂZURI : UNE VIE DÉDIÉE \\ À FORGER LA CULTURE LETTRÉE DE PIURA
}

\section{CARLOS ROBLES RÁZURI: A LIFE DEDICATED TO FORGING PIURA'S LITERATE CULTURE}

\author{
Juan Carlos Adriazola Silva
}

Resumen:

La Academia Peruana de la Lengua en su decidida y permanente tarea de descentralizar sus actividades académicas fuera de la capital de la República, y como una forma de integrar y hacer participes de sus proyectos a lingüistas, lexicólogos y lexicógrafos del interior del país, organiza congresos, simposios y talleres que tributa a una persona representativa de la cultura y de las letras del lugar donde se realiza el evento. Con este propósito, tocó a la ciudad de Piura, del 18 al 20 de agosto de 2010, ser la sede del V Congreso Internacional de Lexicología y Lexicografía, el cual estuvo dedicado a homenajear a Carlos Robles Rázuri. ¿Quién es este personaje? ¿Cuáles son sus méritos? ¿Cuál es la trascendencia de su obra? Este artículo biográfico intenta dar respuesta a estas interrogantes. 


\section{Résumé:}

L'Académie Péruvienne de la Langue dans sa tâche permanente et décidée de décentraliser ses activités académiques en dehors de la capitale Républicaine, et comme une manière d'intégrer et de faire partage ses projets aux linguistes, lexicologues et des lexicographes de l'intérieur du pays, elle organise des congrès, des symposiums et les ateliers qui rendent hommage à une personne représentative de la culture et des lettres du lieu où l'évènement est réalisé. Avec cet objectif, la ville de Piura fut élue, du 18 août au 20 août 2010, être le siège du V Congrès International de Lexicologie et de Lexicographie dédié à rendre hommage à Carlos Robles Rázuri. Qui est ce personnage ? Quels sont ses mérites ? Quelle est la transcendance de son oeuvre ? Cet article biographique essaie de donner la réponse à ces interrogatrices.

\section{Abstract:}

The Fifth Congress of Lexicology and Lexicography was dedicated to honouring Carlos Robles. This biographical article focuses on his merits and transcendency of his work.

\section{Palabras clave:}

Educación; cultura; habla; letras; historia; periodismo; Piura.

Mots clés:

Education; culture; parole; écriture; histoire; journalisme; Piura.

Key words:

Education; culture; literate; history; journalism; Piura.

Fecha de recepción: $\quad$ 11/09/2010

Fecha de aceptación: $\quad 30 / 09 / 2010$

Carlos René Robles Rázuri vio por primera vez la luz del mundo el 30 de junio de 1916 en la ciudad de San Miguel de Piura. Por muchos años se creyó que su nacimiento se había producido en la provincia liberteña de Pacasmayo, pues algunas referencias biográficas aparecidas 
en algunos libros y revistas piuranas consignan este dato equivocado. El error parte quizá en confundir los orígenes de Carlos Robles Rázuri con los de dos personas muy estrechamente ligadas a él: su primo Ramón Abásolo Rázuri, nacido en Pacasmayo en 1914, y su tío José Vicente Rázuri Cortés, escritor y periodista que nació en Jequetepeque, en 1879. Sin embargo, gracias a la partida de nacimiento que hemos localizado en la Municipalidad Provincial de Piura, queda demostrado documentalmente que su alumbramiento se produjo en la casa materna, ubicada en la calle lea de esta ciudad. ${ }^{1}$

Su padre don Wilfredo Robles provenía de una familia limeña asentada en la Magdalena Vieja, aunque la partida de nacimiento de su vástago le asigna como profesión "arquitecto", no es un dato que se haya confirmado del todo. ${ }^{12} \mathrm{Su}$ madre doña María Luisa Rázuri Coronel era hija de Carlos Rázuri Mena y de María Coronel Alama. El abuelo de Carlos Robles Rázuri era hijo de José Carlos Rázuri Echeandía, y éste a su vez, lo era del procer de la Independencia Andrés Rázuri Estéves con su esposa María Josefa Echeandía Ramos, quienes contrajeron nupcias en 1834 y fundaron su hogar y tronco familiar en la hacienda Tambogrande. ${ }^{3}$

1 La información (30/VI/1916) puede verificarse en la Partida de Nacimiento de Carlos Robles Rázuri, $\mathrm{N}^{\circ} 74$, folio $\mathrm{N}^{\circ} 74$, datos registrados una década después, el 6 de marzo 1926.

2 Don Wilfredo Robles de quien se sabe poco, no debió haber vivido muchos años al lado de su mujer e hijos. De acuerdo a las partidas de nacimiento que se han consultado en la Oficina de Registro Civil de la Municipalidad de Piura, los tres niños Robles Rázuri fueron registrados por personas distintas al padre (Víctor Acisclo Sánchez, Pedro Alejandrino Alama). Años después, la madre de Carlos Robles conoció y tuvo larga convivencia con un reputado notario piurano, don Víctor Sánchez Condemarín, quien se constituyó en el padre putativo de nuestro personaje. En su notaría, que se encontraba frente a la iglesia de San Francisco, al costado derecho del desaparecido diario La Industria, el joven Carlos Robles aprendió a valorar los documentos y a compulsarlos. Allí nació, quizá, su vocación a la historia y a las letras.

Vid. RAZURI AGUILAR, Miguel entrevistado en su domicilio por Juan Carlos Adriazola Silva. Piura, martes 20 de julio de 2010, 2 p.m.; Partidas de Nacimiento de 1913, 1917 y 1926 de la Oficina de Registro Civil de la Municipalidad de Piura.

3 MOYA ESPINOZA, Reynaldo. "El matrimonio de José Andrés Rázuri con doña María Josefa Echeandía”. Correo, Piura, lunes 10 de junio de 1985, p. 5. 
Carlos René Robles Rázuri fue el segundo hijo de sus padres, la primogénita de esa relación se llamó María Hortensia (nacida en 1913 y fallecida pocos años después). Luego nació su hermano menor: Gilberto Rogelio, quien, con los años, llegaría a ser médico de profesión gracias a la ayuda y protección de su tío José Vicente Rázuri.

Robles Rázuri empezó los estudios primarios en el antiguo Colegio Salesiano de la calle Libertad, del cual era vecino, pues su casa daba a espaldas de éste, en la esquina de la calle Lima con Lambayeque. Más tarde, continuó la secundaria en el Colegio Nacional San Miguel, que por aquellos días se ubicaba frente al plantel de los padres salesianos y colindaba con la Iglesia de El Carmen, en la Plaza Merino. Fue un alumno aplicado y de conducta disciplinada, y demostró siempre predilección por las letras, antes que por las ciencias. Así lo demuestran sus calificativos que hemos podido observar en los libros de actas que obran en el archivo histórico del Colegio San Miguel. Perteneció a la promoción 1934, conformada por 26 personas, entre las cuales se encontraba curiosamente también su hermano Gilberto Rogelio y su primo Ramón Abásolo Rázuri (con los años notable abogado y tres veces diputado por Piura) a quien Robles admiró siempre y expresó afecto especial; es justamente con su primo Ramón y secundado por sus amigos de aula Miguel Novoa y Florentino La Torre, con quien Robles hizo sus primeras armas en el periodismo, al fundar una revista escolar de nombre Sayari (o Sayarich), ${ }^{4}$ la cual tuvo mucha acogida entre alumnos y profesores por sus artículos de actualidad, trabajos literarios y el tono satírico de algunas de sus notas.

Es interesante señalar que los estudios secundarios tenían entonces el rigor y la profundidad de contenido que lograba que sus egresados pudieran pronto asumir roles de importancia en el mundo laboral. Al concluir la secundaria, Robles Rázuri obedece al fuerte llamado de su vocación periodística. Su maestro Néstor Martos, a la sazón director de La Industria de Piura, le abrió las puertas en el diario fundado por el doctor Miguel Cerro. En este medio informativo se desempeñó como redactor

4 REQUEJO RODRIGUEZ, Juan Vicente. "Periodismo en Piura”. En Época, núm. 27, Piura, enero-febrero, 1969, p. 7; CORNEJO UBILLUS, Edmundo. Calendario Cívico de Piura. Piura, Municipalidad Provincial de Piura. 2006. p. 170, (1048). 
y articulista de polendas. Sus primeros trabajos periodísticos nos dan indicio del cuidado gramatical con que solía preparar cada uno de los textos que publicaba. Fue forjando desde entonces un estilo personal que perfeccionó con el devenir del tiempo.

En 1935 se cumplió el primer centenario del Colegio San Miguel, los festejos de esa conmemoración exigieron elaborar un programa especial que se llevó a cabo del 28 al 30 de septiembre. La ciudad se vistió de gala. Hubo misa en la Iglesia matriz, fuegos artificiales, paseo de antorchas, retretas, romerías, medallas de oro y, por supuesto, discursos solemnes. Para ello el director del plantel, doctor Francisco Lizarzaburu, y el Comité organizador seleccionaron cuidadosamente personas representativas vinculadas al colegio para que hicieran uso de la palabra. Por unanimidad se escogió a Carlos Robles Rázuri para que, en nombre de los ex alumnos, diera el discurso de orden. Lo que nos demuestra la enorme consideración que le tenían sus antiguos maestros.

En 1938, Carlos Robles Rázuri, a los 20 años de edad, y sin poseer título pedagógico, ${ }^{5}$ ingresó a la docencia en el Colegio Nacional San Miguel como profesor, primero, de la asignatura de Historia General, y, al año siguiente, de la asignatura de Castellano, que le heredaron sus maestros Francisco Xándoval y Félix Rafael Manrique. Al inaugurarse en $1953 \mathrm{el}$

$\overline{5}$ Como bien lo ha señalado el profesor Estrada Morales en sus recuerdos del Colegio San Miguel, el ejercicio de la docencia escolar no exigía en esos años la posesión de título pedagógico. Personas de diversas profesiones u oficios: como abogados, agrónomos, ingenieros, físicos, médicos, matemáticos, periodistas, literatos, músicos, pintores, sacerdotes, etc., podían muy bien realizar labores de enseñanza secundaria, siempre y cuando se basaran en los Programas Oficiales establecidos por el Ministerio de Educación del Perú. Con el tiempo, fueron llegando a San Miguel los pedagogos de carrera que provenían de las primeras promociones de las Escuelas Normales Urbanas de Trujillo, Lima y Piura (1943). Hubo en el caso específico de Carlos Robles Rázuri una consideración especial por parte del Dr. Francisco Lizarzaburu, consideración que se sustentaba en la amplia cultura de lo universal y de lo peruano que exhibía nuestro personaje, fruto de su propia disciplina y su vocación a las letras que le venía por parte de la familia de su madre.

ESTRADA MORALES, José. San Miguel Miscelánea del alma Piurana 1936-1940. Piura, edición particular del autor (de su serie "Cuadernos de Piuranidad" No 7), 12003), p. 16 y MACHUCA MAZA, Hildamaria. Personajes ilustres de Piura. Álbum coleccionable de El Tiempo, Piura, 2004. p. 36.

Bol. Acad. peru. leng. 50(50), 2010 
amplio y moderno local de la Gran Unidad Escolar San Miguel, en la calle del Libertador San Martín (barrio Buenos Aires), Carlos Robles Rázuri, al igual que sus compañeros docentes, siguió prestando servicio educativo en su alma mater. Allí permanecería hasta 1970, año en que finalmente se jubiló, tras cosechar nombradía y dejar un grato recuerdo entre sus colegas y, sobre todo, en ex alumnos y ex alumnas que lo respetaban y le guardaban admiración. Así lo recuerda su discípulo Juan Antón y Galán de la promoción 1948:

(...) Lo veía llegar al viejo San Miguel, todos los días lozano y fuerte, con paso calmado, mirada altiva y escrutadora, con su hato de libros bajo el brazo, el corazón henchido de esperanza y la mente lúcida ahíta de ilusiones, con nuevos ideales por un mundo mejor. Sereno, grave, su gesto adusto jamás fue sinónimo de intemperancia. Denunciaba un corazón donde sólo anidaba la bondad, la tolerancia, [la] misericordia, [la] magnanimidad. Parecía que nunca supo de golpes del destino, pues sus labios jamás se movieron para espetar un grito de repulsa.

Con la primera luz del día, le veíamos siempre venciendo calles y plazuelas, con paso calmo hacia el Colegio. Su frente amplia y sus gruesos lentes reflejaban la ardiente luz del bendito rey del cielo. Las gentes le miraban con admiración y saludaban con respeto. Nunca el fiero vendaval del desprecio y la ingratitud, ni de la envidia y la malevolencia se ensañaron contra él, porque todos le fuimos gratos. (...)Todos habíamos sido sus alumnos. Todos aprendimos sus percentiles y sus listados de vulgarismos con entereza y devoción. No podíamos olvidarlo. El nos conocía a todos". ${ }^{6}$

Robles Rázuri fue docente del Colegio Nacional San Miguel en una de las épocas en que los profesores le dieron brillo al plantel. A su generación pertenecieron otros maestros singulares como: Néstor Martos Garrido (Historia Universal con tres cursos por año: Oriente, Grecia, Roma, Edad

6 ANTON Y GALÁN, Juan. “Remembranza por Carlos Robles”. En Época, núm. 256, año XXVII, Piura, enero-febrero, 1993. p. 25. 
Media, Tiempos Modernos y Época Contemporánea; además Historia de la Cultura); Augusto Moscol Carrera (Edad Media y tiempos Modernos); Julio Valdéz Garrido (Historia del Perú y América, Educación Cívica); Oscar Rojas Goycochea (Historia del Perú); R.P. Jesús Santos García (Religión y Filosofía); Augusto Cevallos Timoteo (Historia de la Literatura) Neptalí Plaza Espino (Geografía General); Juan Roberto Velasco (Geografía del Perú y del Mundo); Ramón Abásalo Rázuri (Geografía General); Roberto Nolte Garcés (Aritmética y Algebra); Manuel Cortés Coronel Zegarra (Geometría y Trigonometría); Guillermo Gullman Lapouble (Economía y Política); Luis Altuna Sandoval (Psicología); Francisco Escudero Franco (Anatomía, Fisiología e Higiene); Daniel Vidarte Barboza (Química); Víctor Lema Pérez, Joaquín Ramos Ríos y Guillermo Zela Koort (Inglés); Ernesto Drouard Hansen (Física, Caligrafía, Dibujo y Trabajo Manual); Wilfredo Obando Vásquez (Música y Canto); Víctor Garay (Dibujo); Sub- Teniente EP Ricardo Martínez Tapia (Instrucción PreMilitar); Lorenzo Palomino Chávez y Oscar Bringas (Educación Física). ${ }^{7}$

Ocupó en San Miguel varios cargos y responsabilidades: profesor de Castellano y Literatura, director de la revista escolar, Jefe del Departamento de Normas Educativas, director de estudios y organizador permanente de actividades artísticoculturales. En Piura tuvo también la oportunidad de impartir clases en los colegios Salesiano y San Ignacio de Loyola, de varones, y Nuestra Señora de Fátima y de Lourdes, de mujeres. En múltiples ocasiones fue jurado calificador de los rigurosos exámenes semestrales y de fin de año que, con balotarlo en mano, se tomaban tanto en San Miguel como en los colegios que lo invitaban a participar. Como pedagogo fue permeable a las reformas educativas y a las corrientes innovadoras.

7 RUMICHE AYALA, Antonio. "El Colegio San Miguel de los años cuarenta" (el autor pertenece a la promoción 1942-1946). En Época, núm. 356, año XXXVIII, Piura, septiembre, 2004. 
León Zaldívar, José Albán Ramos, Elvira Castro de Quirós, Jorge Moscol Urbina, Carmen Arguelles de Manrique, Rodolfo Ramos Seminario, Miguel Antonio Varillas Velásquez, Luis Ginocchio Feijó, Edmundo Arámbulo Palacios, Federico Varillas Castro y muchos otros intelectuales más el Grupo Literario y Artístico Piura (más conocido por su sigla GLAP), grupo de enorme trascendencia en la vida cultural de la ciudad y cuya vigencia se extendió por cerca de veinte años ininterrumpidos. En la revista institucional del GLAP denominada Perfil Piurano, se hallan publicados buena cantidad de artículos escritos por nuestro personaje y sus colegas de generación. ${ }^{8}$

Notable fue también su labor como director del Órgano Oficial del Club Grau, en el cual escribió "Piura y el Club Grau" (1949-1960), continuación de la historia institucional emprendida años atrás por su tío José Vicente Rázuri autor del libro El Club Grau en la historia de Piura, ${ }^{9}$ publicada en dos partes: 1885-1947 / 1947-1948.

Desde temprana juventud, Carlos Robles Rázuri sintió, asimismo, una fuerte vocación investigadora, especialmente por el pasado histórico piurano y por la lengua de su gente. El prestigio ganado en estos campos lo llevó a ocupar el cargo de primer Director del Archivo Departamental de Piura, a partir del 1 de junio de 1976. Por aquel tiempo, el Archivo funcionaba en la hoy desaparecida casona Eguiguren de la calle Lima 749, en donde se le vio trabajar de forma tesonera y permanente por conservar y reunir en un solo repositorio el patrimonio archivístico regional, a tal punto que Juan Paz Velásquez le ha bautizado con el nombre de "archivero mendigo" por emular de algún modo al tradicionista Ricardo Palma. ${ }^{10}$

8 VARILLAS VELÁSQUEZ, Miguel Antonio. "El GLAP en la historia de la Cultura Piurana". En Época, núm. 347, año XXXVII, Piura, julio, 2003, pp. 27-28.

9 ROBLES RÁZURI, Carlos. "Piura y el Club Grau”. En Órgano Oficial del Club Grau, núm. 6, año 3, Piura, 1971, p. 4.

10 PAZ VELÁSQUEZ, Juan. "Robles Rázuri: Archivero Mendigo". En Época, núm. 244, año XXV, Piura, abril-mavo, 1991. 
cultural predominante en esas décadas. La cultura, la educación y el arte debían ser medios de redención para el hombre. Fue un melómano impenitente, admirador de Beethoven, Handel, Grieg, Schubert y Rossini. A sus alumnos y amigos trató siempre de inculcar la vida y obra de los grandes compositores, y muchos le recuerdan también por esta faceta.

Fue un tenaz e irreductible defensor de la libertad de expresión y de opinión de los ciudadanos y, sobre todo, de los hombres de prensa. En la década del 30 gozó de una pasantía en la Universidad Interamericana de Nueva York, concedida por la Embajada de los Estados Unidos. Después de muchos años, gracias a una ley especial dada por el Congreso peruano, pudo, como muchos otros colegas, obtener su título profesional de periodista en la Universidad Nacional Mayor de San Marcos (1966). Perteneció por largos años al Centro Federado de Periodistas y al Colegio de Periodistas del Perú Consejo Directivo Piura, gremio éste en el cual ocupó de 1984 a 1986 el cargo de Primer Vice-Decano; y de 1989 a 1991, fue elegido, en reñidas elecciones, ${ }^{11}$ como Decano de dicho colegio profesional.

Dentro de la actividad periodística, don Carlos Robles Rázuri marcó huella indeleble en sus contemporáneos. En sus años noveles de cronista fue un sobresaliente satírico, pero luego se dejó vencer por la solemnidad del lenguaje. Sus escritos iniciales los firmó con el seudónimo de Aristófanes. ${ }^{11} 12$ Desde entonces demostró no sólo dominio del idioma sino una clara inclinación por hacer vivir al lector el lado risueño de la vida. De forma paralela se dedicó a la investigación histórica y lingüística, cuya más importante producción volcó en letras de molde en la revista Época y en los diarios La Industria, Correo y, especialmente, El Tiempo de Piura.

En forma de libro, cuatro son los trabajos publicados en vida por Robles Rázuri: un texto escolar para el nivel secundario titulado Castellano

11 Vid. Diario El Tiempo, Piura, sábado 26 de noviembre de 1988, p. 4; lunes 5 de diciembre de 1988, p. 3; jueves 12 enero de 1989, p. 3; y martes 24 de enero de 1989, p. 3.

12 ESTRADA MORALES, José. "Carlos Robles Rázuri”. El Tiempo, Piura, domingo 18 de enero 
(s,f.), Breve Antología de Poetas Piuranos (1950), Historia de Piura (1975), Aspectos Geográficos de la Historia de Piura (1975) y, como editor de los documentos de archivo recopilados y transcritos por don Enrique del Carmen Ramos, Documentos Históricos (1973).

Aunque los artículos, crónicas, comentarios y ensayos de Robles Rázuri consagrados a personajes, costumbres e instituciones piuranas son innumerables, por su temática éstos pueden clasificarse en tres grandes grupos: los de tipo histórico, los de tipo literario'artístico y los de tipo lingüísticodexicográfico. En temas históricos sobresalen las fichas coleccionables de: "El Libro del Cabildo 1824'1832" (1982'1984) y "Sucesos Piuranos" (1989); en temas literario-artísticos: "El Tondero Piurano"(1987); y en cuanto a temas lingüístico-lexicográficos su mayor aporte se encuentra en: "La Lengua de los Piuranos" (19824984). Todos estos trabajos intelectuales, se fueron dando a conocer al público lector de El Tiempo por entregas diarias o con cierta periodicidad semanal, lo que generaba gran expectativa y curiosidad entre los coleccionistas. Cada obra de Robles Rázuri fue escrita con mucho amor a la tierra y con total desinterés; fue su homenaje personal a la patria chica, a la cual se sentía vinculado física y espiritualmente.

Cultivó amistad fraterna con casi todos los intelectuales piuranos de su tiempo y nunca escatimó elogios para quienes, como él, ayudaban a sentar las bases de la piuranidad. Así lo expresa en carta dirigida al historiador paiteño Reynaldo Moya Espinoza, el 10 de julio de 1982, cuando al comentar su Breve Historia de Piura, dice:

Dilecto amigo:

Los pueblos y los hombres son grandes y dejan huella en el tiempo por la obra positiva que realizan; y, si la tarea que realizan es cultural, su impronta es eterna.

Así ha ocurrido con los notables piuranos del pasado y así ha de ocurrir con los de la presente generación. 
Procede lo anterior porque su obra Breve Historia de Piura es un verdadero y real monumento en el $450^{\circ}$ aniversario de la fundación de la primera ciudad fundada por los españoles en el Perú en 1532, en territorio precisamente de su provincia, lo cual la hace más valedera todavía, y más satisfactoria para los piuranos que hemos de vivir una real descentralización y enorgullecemos del quehacer de todas las provincias. Con su obra está usted probando que los piuranos podemos realizar obras de calidad y profundidad que en nada desmerece a los mejores estudios que puedan hacer mentes lúcidas de otras partes del Perú, y sobre todo no hay necesidad de recurrir a foráneos para que juzguen nuestros trabajos o les den el espaldarazo. ${ }^{13}$

Luego de dilatada experiencia docente, el Ministerio de Educación del Perú le confirió a Carlos Robles Rázuri las Palmas Magisteriales en el Grado de Educador, acto que se llevó a cabo el 5 de julio de 1984, Día del Maestro; se sumó a este reconocimiento el Concejo Provincial de Piura, presidido por su alcalde, el doctor Luis Antonio Paredes Maceda.

En los últimos meses de 1990, la salud de nuestro personaje se vio muy deteriorada, y hubo de ser internado de emergencia en el Hospital Cayetano Heredia. Hasta allí fueron a visitarlo sus colegas periodistas y docentes, ex alumnos y amigos de todas las edades. Nunca contrajo nupcias, ni tuvo descendencia, pues toda su vida la dedicó al fomento de la educación, el periodismo y la investigación histórica. Además, pocos saben que él fue un hijo fiel y amoroso con su madre, pues veló siempre por su salud y bienestar hasta que ella murió anciana el 12 de febrero de 1978.

A las 2 de la madrugada del 4 de enero de 1991, día en que se conmemoraba el Grito Libertario de Piura de 1821, don Carlos Rene

13 ROBLES RÁZURI, Carlos carta a Reynaldo Moya, Piura, 10 de julio 1982 (publicada en Correo, Piura 11 de julio de 1982, p. 5), cit. por MOYA ESPINOZA, Reynaldo. Diccionario histórico biográfico regional. Siglo XX. Sullana, Fondo Editorial Municipalidad Distrital de Bellavista y Centro Cultural Tallán (Genaro Maza y Mario Palomino editores), 1993. p. 252.

Bol. Acad. peru. leng. 50(50), 2010 
Robles Rázuri entregó su alma al Creador. Sus restos mortales, llevados por sus amigos al Colegio Nacional San Miguel, fueron luego trasladados en solemne cortejo a la iglesia del Santísimo Sacramento para oficiar la misa de corpore in sepulto. Pocas horas después se depositaron en el nicho A3, del cuartel "Todos los Santos" del Cementerio San Teodoro de Piura.

Una semana después de su fallecimiento, José Hipólito Estrada Morales, al escribir sobre el aporte intelectual que el extinto piurano ha dejado a las generaciones venideras, dice:

"Cuatro huellas que proceden desde sus años mozos predominan en su obra intelectual: su amor a la tierra, su piuranidad, su fe en la educación, el arte y la cultura como medios para redimir al hombre; su convicción del esplendor y la trascendencia del pasado histórico piurano; y su aliento permanente y positivo como animador intelectual en el ambiente provinciano de Piura. No fue hombre de espíritu quieto. Carlos Robles Razuri como periodista o educador, como amante del pasado histórico o como buceador en los ámbitos propios de la cultura piurana ha sido un elemento muy significativo. Siempre sembrador y humilde. Lo que ha dejado es camino abierto para ir conociendo -y queriendo más- a Piura". ${ }^{14}$

\section{BIBLIOGRAFIA}

ANTON Y GALÁN, Juan. "Remembranza por Carlos Robles". En Época, núm. 256, año XXVII, Piura, enero-febrero, 1993. p. 25.

CORNEJO UB1LLUS, Edmundo. Calendario Cívico de Piura. Piura, Municipalidad Provincial de Piura. 2006.

14 ESTRADA MORALES, José. "Carlos Robles y sus obsesiones”. El Tiempo, Piura, viernes 11 de enero de 1991, p. 6. 
EL TIEMPO, Piura, sábado 26 de noviembre de 1988, p. 4; lunes 5 de diciembre de 1988, p.3; jueves 12 enero de 1989, p.3; y martes 24 de enero de 1989 , p. 3.

ESTRADA MORALES, José. "Carlos Robles y sus obsesiones”. El Tiempo, Piura, viernes 11 de enero de 1991, p. 6.

. "Carlos Robles Rázuri”. El Tiempo, Piura, domingo 18 de enero de 1998.

San Miguel Miscelánea del Alma Piurana 19364940. Piura, edición particular del autor ("Cuadernos de Piuranidad" N 7), [2003].

MACHUCA MAZA, Hildamaría. Personajes ilustres de Piura. Álbum coleccionable de El Tiempo, Piura, 2004.

MOYA ESPINOZA, Reynaldo. Diccionario histórico biográfico regional. Siglo XX. Sullana, Fondo Editorial Municipalidad Distrital de Bellavista y Centro Cultural Tallán, 1993.

. "El matrimonio de José Andrés Rázuri con doña María Josefa Echeandía". Correo, Piura, lunes 10 de junio de 1985, p. 5.

PAZ VELÁSQUEZ, Juan. "Robles Rázuri: Archivero Mendigo". En Época, núm. 244, año XXV, Piura, abril-mayo, 1991.

REQUEJO RODRÍGUEZ, Juan Vicente. "Periodismo en Piura". En Epoca, núm. 27, Piura, enero-febrero, 1969, p. 7.

ROBLES RÁZURI, Carlos. "Piura y el Club Grau”. En Órgano Oficial del Club Grau, núm.6, año 3, Piura, 1971.p. 4.

. "La Lengua de los Piuranos". El Tiempo, Piura, 30 de junio de 1982. p. 4. 
. "Breve Historia de Piura es monumento al 450 aniversario" (carta a Reynaldo Moya, Correo, Piura, domingo 11 de julio de 1982, p. 5.)

RUMICHE AYALA, Antonio. "El Colegio San Miguel de los años cuarenta". En Época, núm. 356, año XXXVIII, Piura, septiembre, 2004.

VARILLAS VELÁSQUEZ, Miguel Antonio. "El GLAP en la historia de la Cultura Piurana". En Época, núm. 347, año XXXVII, Piura, julio, 2003.

\section{OTROS}

LIBRO DE ACTAS ESCOLARES DE 1934. Piura, Colegio Nacional San Miguel, 1934.

REGISTRO CIVIL DE LA MUNICIPALIDAD DE PIURA. Partidas de Nacimiento de 1913,1917 y 1926.

RAZURI AGUILAR, Miguel entrevistado en su domicilio. Piura, martes 20 de julio de 2010, 2 p.m.

\section{Correspondencia:}

\section{Juan Carlos Adriazola Silva}

Doctorando de Ciencias de la Educación en la Universidad Nacional de Piura.

Correo electrónico: adriazola46@yahoo.es 